\title{
Mathematical Development and Evaluation of Forecasting Models for Accuracy of Inflation in Developing Countries: A Case of Vietnam
}

\author{
Nhu-Ty Nguyen and Thanh-Tuyen Tran \\ International Relations Office, Lac Hong University, No. 10 Huynh Van Nghe Street, Bien Hoa, Dong Nai 71000, Vietnam
}

Correspondence should be addressed to Nhu-Ty Nguyen; nhutynguyen@gmail.com

Received 26 September 2014; Accepted 9 February 2015

Academic Editor: Ufuk Yolcu

Copyright (C) 2015 N.-T. Nguyen and T.-T. Tran. This is an open access article distributed under the Creative Commons Attribution License, which permits unrestricted use, distribution, and reproduction in any medium, provided the original work is properly cited.

Inflation is a key element of a national economy, and it is also a prominent and important issue influencing the whole economy in terms of marketing. This is a complex problem requiring a large investment of time and wisdom to attain positive results. Thus, appropriate tools for forecasting inflation variables are crucial significant for policy making. In this study, both clarified value calculation and use of a genetic algorithm to find the optimal parameters are adopted simultaneously to construct improved models: ARIMA, GM(1,1), Verhulst, DGM(1,1), and DGM(2,1) by using data of Vietnamese inflation output from January 2005 to November 2013. The MAPE, MSE, RMSE, and MAD are four criteria with which the various forecasting models results are compared. Moreover, to see whether differences exist, Friedman and Wilcoxon tests are applied. Both in-sample and out-of-sample forecast performance results show that the ARIMA model has highly accurate forecasting in Raw Materials Price (RMP) and Gold Price (GP), whereas, the calculated results of GM(1,1) and DGM $(1,1)$ are suitable to forecast Consumer Price Index (CPI). Therefore, the ARIMA, GM(1,1), and DGM(1,1) can handle the forecast accuracy of the issue, and they are suitable in modeling and forecasting of inflation in the case of Vietnam.

\section{Introduction}

Vietnam is in the process of socioeconomic development and integration into the world economy, so Vietnam would have more investment opportunities and economic development to boost exports of goods and new intrusion economy globally. Besides, Vietnam has to face many challenges in open economy like today, especially the stiff competition in the business world. However, according to the recent report, Vietnam Report (Q3-2013), in the third quarter of 2013, growth continued and increased at 5.54\% approximately, which brought Gross Domestic Product (GDP) to 5.14\% higher in the first 9 months of 2013 than the same period of 2012. Fourth-quarter GDP forecasted to grow at $6 \%$ in aggregate demand because the economy will be more positive changes in light of the seasonal nature and impact of the policy lag (about 9 months) in the last months. Thus, the annual growth forecast is somewhat better than the original forecast of Financial Supervisory Commission countries (5.3\%). Some macroeconomic indicators have moved the more positive signs in January as production, exports, inflation, and Foreign Direct Investment (FDI) [1].

FDI Inflows, Positive and Aggressive Capital Structure. As of October, 2013, FDI attracted over $\$ 19$ billion, an increase of $65.6 \%$ and the realized FDI reached 9.58 billion USD, up to $6.4 \%$. Fields of industrial production, manufacturing and processing, and electronics are still the most attractive field; which means these fields accounted for $86.4 \%$ of the total capital during 9 months that also means they got two-time growth over the same period to help Vietnam improve longterm production capacity and develop ancillary industries (GSO-VN).

In the first 10 months of the year, exports continued to grow (up to $15.2 \%$ ), being the lowest deficit in recent years ( $\$ 187$ million deficit). In particular, FDI remains as the mainstay of exports and accounted for $61.3 \%$ of total exports (up to $27.2 \%$ compared to the same time of the previous 

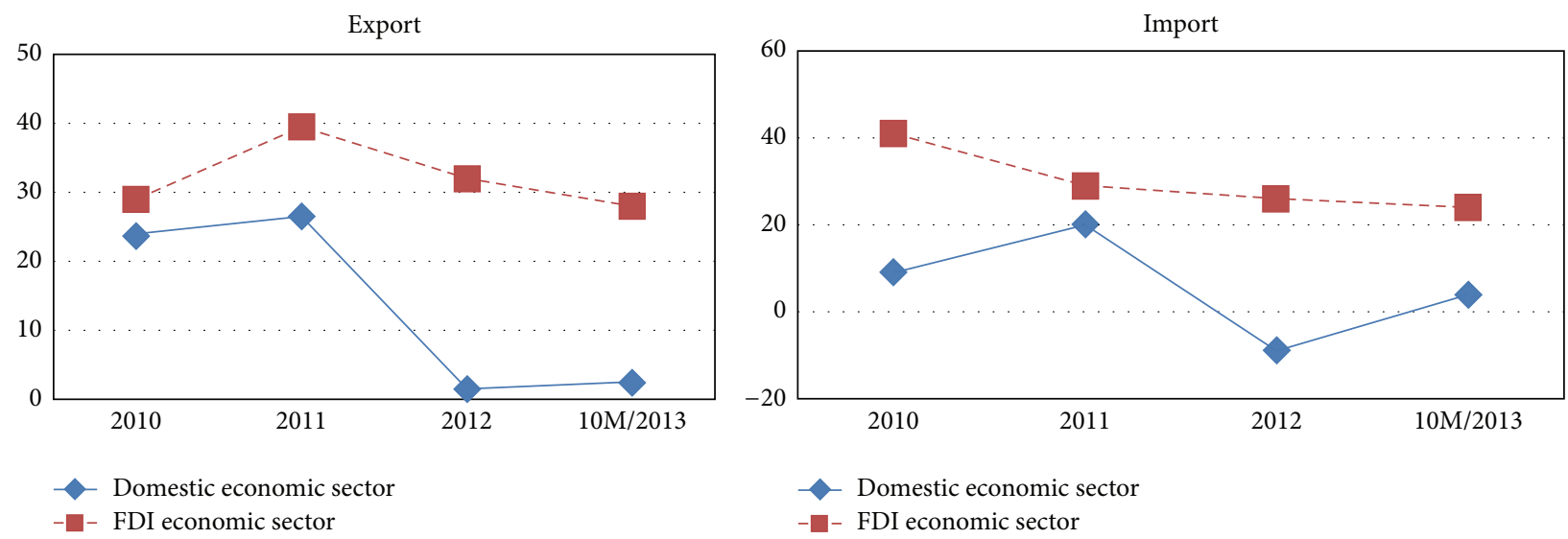

FIGURE 1: Growth rate of export and import activities (\%) (source: General Statistics Office of Vietnam (GSO-VN)).

year). Meanwhile, due to the impact of domestic policies, import and export activities of the business sectors, rather than FDI, in the country have declined since 2011 (Figure 1). The trend is somewhat improved in 2013 compared with 2012 when the export operations and import of this area have turned up to $3 \%$ and $3.5 \%$ over the same period. Import growth group for production materials and machinery for production also increased significantly showing promising recovery in brighter domestic production.

However, in the marketing economy, the most prominent and important issue influencing the whole economy is inflation. This is a complex problem requiring a large investment of time and wisdom to attain positive results of study. Therefore, fighting inflation is not only the task of government but also the task of all people and businesses [2]. Inflation affects the entire national economy and society, especially workers. Monthly inflation tends to rise since June, peaking in the first two months of quarter 3, 2013 (at 7.29\% and $7.5 \%$ in July and August, resp.). By the mean time, CPI of the months is mainly influenced by the seasonal adjustment (cost of goods and services by state management) rather than the fundamentals of inflation; in particular, aggregate demand is still low (Figure 2). In November, 2013, compared with the same period, inflation fell to its lowest level since 2010 (5.78\%), but inflation is still in its trend. In quarter 4, 2013, factor analysis indicates that this cycle is the quarter holding the highest growth rate in the year, but the demand is still weak. Thus, this would substantially limit price increasing in the coming months. The main factors causing price increases in the quarter include increased food and catering services and the demand for the seasonal shopping months, Tet Holiday (Traditional Vietnamese Lunar New Year).

Thus, this research topic is to contribute a small part of studying in order to find and control inflation and to maintain stable development of the economy as mentioned above. Moreover, the inflation of Vietnam in recent years is the main subject in this study by collecting data from 2005 to November, 2013. The research tries to figure out the problems around Vietnamese inflation, apply forecasting methods to find out the inflation rules in Vietnam, and choose the applicable

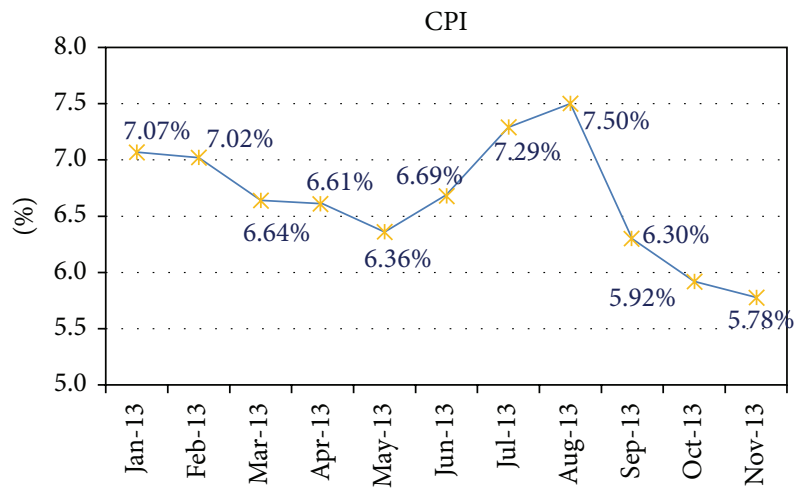

FIgure 2: The Vietnamese CPI from January to November, 2013. Notes: This figure shows the year-on-year Consumer Price Index (CPI), that is, price index of January, 2013 to January, 2012, for example.

forecasting model in order to predict, analyze, and state out solutions to combat inflation in Vietnam in the future.

The research questions are as follows:

(1) Are there any differences between forecasting models in this study?

(2) How do the two improved models of $\operatorname{GM}(1,1)$, $\operatorname{DGM}(1,1)$, and $\operatorname{DGM}(2,1)$ perform?

(3) What are the results of Vietnamese inflation for the next few years?

(4) What are the suitable models for this issue?

\section{Literature Review}

2.1. Inflation. According to Marques et al. [3], inflation is the percentage change in the value of the Consumer Price Index (CPI) on a year-on-year basis. It effectively measures the change in the prices of a basket of goods and services in a year. 
Formula for Calculating is as follows:

$$
L_{t}=\frac{\left(P_{t}-P_{t-1}\right)}{P_{t-1}} \times 100 \%,
$$

where $t$ is the point of period of which inflation is calculated, $L_{t}$ is the inflation in the period $t, P_{t}$ is the index value (e.g., CPI, RMP, etc.) at the period $t, P_{t-1}$ is the index value (e.g., CPI, RMP, etc.) at the period $t-1$.

Description. Inflation can happen based on the following: (1) the demand and supply of money that are unstable, (2) the cost of producing and distributing products/goods, or (3) the taxes on products/goods increasing. Inflation means price level of goods/products or services rises; this causes the value of the economic currency to reduce when the price level rises, each unit of currency buys fewer goods and services compared with the same period before.

It has its worst impact on consumers (discussed more in the final section of this research). However, contrary to its negative effects, a moderate level of inflation characterizes a good economy. If an economy keeps the inflation rate as low as possible (e.g., under 2 or $3 \%$ ), that economy will encourage people to consume more or to borrow more because the interest rate stays low at the period. Hence, the governments as well as the central banks always strive to achieve a limited level of inflation [4]. In addition, the forecasting of inflation interests both market practitioners and central banks [5], so these works should be encouraged to provide the people of that economy with a whole picture about their investment and/or spending.

2.2. Grey Systems Modeling. Grey system theory [6] is a truly multidisciplinary theory dealing with grey systems that are characterized by both partially known and partially unknown information. It has been widely used in several fields such as agriculture, industry, and environmental systems studies. As an essential part of grey system theory, grey forecasting models have gained in popularity in time-series forecasting due to their simplicity and ability and high precision to characterize an unknown system by using as few as four data points [7-9].

2.2.1. Basic $\operatorname{GM}(1,1)$ Model. The $\operatorname{GM}(1,1)$, which is pronounced as "Grey Model First Order One Variable," can only be used in positive data sequences [6]. This model is a timeseries forecasting model. The differential equations of the $\mathrm{GM}(1,1)$ model have time-varying coefficients.

Let $X^{(0)}=\left(x^{(0)}(1), x^{(0)}(2), \ldots x^{(0)}(n)\right)$ be sequences of raw data. Denote its accumulation generated sequences by $X^{(1)}=\left(x^{(1)}(1), x^{(1)}(2), \ldots, x^{(1)}(n)\right)$. Then,

$$
x^{(0)}(k)+a x^{(1)}(k)=b
$$

is referred to as the original form of the $\operatorname{GM}(1,1)$ model, where the symbol GM(1,1) stands for first order grey model in variables [10]. Consider

$$
x^{(0)}(k)+a z^{(1)}(k)=b
$$

as the basic form of this model if $Z^{(1)}=\left(z^{(1)}(2), z^{(1)}(3)\right.$, $\left.\ldots, z^{(1)}(n)\right)$, that is $z^{(1)}(k)=(1 / 2)\left(x^{(1)}(k)+x^{(1)}(k-1)\right)$, with $k=2,3, \ldots, n$.

Theorem 1. Let $X^{(0)}, X^{(1)}$, and $Z^{(1)}$ be the same as the above except that $X^{(0)}$ is nonnegative. If $\widehat{a}=(a, b)^{T}$ is a sequence of parameters, and

$$
\begin{aligned}
& Y=\left[\begin{array}{c}
X^{(0)}(2) \\
X^{(0)}(3) \\
\vdots \\
X^{(0)}(n)
\end{array}\right], \\
& B=\left[\begin{array}{ccc}
-Z^{(1)}(2) & 1 \\
-Z^{(1)}(3) & 1 \\
\vdots & & \vdots \\
-Z^{(1)}(n) & 1
\end{array}\right],
\end{aligned}
$$

then (3) satisfies $\widehat{a}=\left(B^{T} B\right)^{-1} B^{T} Y$, so, from Theorem 1 notations, if $[a, b]^{T}=\left(B^{T} B\right)^{-1} B^{T} Y$, then $d x^{(1)} / d t+a x^{(1)}=b$ (whitenization equation in (3)).

Theorem 2. Let B, $Y, \widehat{a}$ be the same as in Theorem 1. If $\widehat{a}=$ $[a, b]^{T}=\left(B^{T} B\right)^{-1} B^{T} Y$, then

(1) the solution of $d x^{(1)} / d t+a x^{(1)}=b$ is given by

$$
X^{(1)}(t)=\left(X^{(1)}(1)-\frac{b}{a}\right) e^{-a t}+\frac{b}{a}
$$

(2) the time response sequence of $d x^{(1)} / d t+a x^{(1)}=b$ is given as follows:

$$
\begin{array}{r}
\widehat{X}^{(1)}(k+1)=\left(X^{(0)}(1)-\frac{b}{a}\right) e^{-a k}+\frac{b}{a}, \\
\quad k=1,2, \ldots, n,
\end{array}
$$

(3) the restored values of $x^{(0)}(k)$ 's are given with * marked as equation:

$$
\begin{aligned}
& \widehat{x}^{(0)}(k+1)= \alpha^{(1)} \widehat{x}^{(1)}(k+1)=\widehat{x}^{(1)}(k+1)-\widehat{x}^{(1)}(k) \\
&=\left(1-e^{a}\right)\left(x^{(0)}(1)-\frac{b}{a}\right) e^{-a k} \\
& \\
& \quad k=1,2, \ldots, n .
\end{aligned}
$$

2.2.2. Verhulst Model. The Verhulst model was first introduced by a German biologist Pierre Franois Verhulst. The main purpose of Velhulst model is to limit the whole development for a real system and it is effective in describing some increasing processes, such as an S-curve which has a saturation region. Therefore,

$$
x^{(0)}(k)+a z^{(1)}(k)=b\left(z^{(1)}(k)\right)^{\alpha}
$$


is established as the $\mathrm{GM}(1,1)$ power model, and

$$
\frac{d x^{(1)}}{d t}+a x^{(1)}=b\left(x^{(1)}\right)^{\alpha}
$$

is known as the whitenization equation of $\operatorname{GM}(1,1)$ power model when $X^{(0)}$ is assumed to be a sequence of raw data, $X^{(1)}$ is a sequence of accumulation of generation of $X^{(0)}$, and $Z^{(1)}$ is adjacent neighbor mean of $X^{(1)}$.

Theorem 3. Then,

$$
x^{(1)}(t)=\left\{e^{-(1-a) a t}\left[(1-a) \int b e^{(1-a) a t} d t+c\right]\right\}^{1 /(1-a)}
$$

is the solution of (9).

Theorem 4. With $X^{(0)}, X^{(1)}$, and $Z^{(1)}$ (as shown above), let

$$
\begin{aligned}
& B=\left[\begin{array}{cc}
-z^{(1)}(2) & \left(z^{(1)}(2)\right)^{\alpha} \\
-z^{(1)}(3) & \left(z^{(1)}(3)\right)^{\alpha} \\
\vdots & \vdots \\
-z^{(1)}(n) & \left(z^{(1)}(n)\right)^{\alpha}
\end{array}\right], \\
& Y=\left[\begin{array}{c}
x^{(0)}(2) \\
x^{(0)}(3) \\
\vdots \\
x^{(0)}(n)
\end{array}\right] .
\end{aligned}
$$

Then, the least squares estimate of the parametric sequence $\widehat{a}=$ $[a, b]^{T}$ of $(8)$ is $\widehat{a}=\left(B^{T} B\right)^{-1} B^{T} Y$.

When the power of (8) $\alpha=2$, the resultant model is

$$
x^{(0)}(k)+a z^{(1)}(k)=b\left(z^{(1)}(k)\right)^{2} .
$$

This is the grey Verhulst model, and

$$
\frac{d x^{(1)}}{d t}+a x^{(1)}=b\left(x^{(1)}\right)^{2} .
$$

This is known as the whitenization equation of grey Verhulst.

Theorem 5. The solution of (12) is

$$
\begin{aligned}
x^{(1)}(t) & =\frac{1}{e^{a t}\left[1 / x^{(1)}(0)-(b / a)\left(1-e^{-a t}\right)\right]} \\
& =\frac{a x^{(1)}(0)}{e^{a t}\left[a-b x^{(1)}(0)\left(1-e^{-a t}\right)\right]} \\
& =\frac{a x^{(1)}(0)}{b x^{(1)}(0)+\left(a-b x^{(1)}(0)\right) e^{a t}} .
\end{aligned}
$$

The time response sequence of the grey Verhulst model is

$$
\widehat{x}(k+1)=\frac{a x^{(1)}(0)}{b x^{(1)}(0)+\left(a-b x^{(1)}(0)\right) e^{a k}} .
$$

2.2.3. Discrete Grey Models (DGM): A Discretization of the $G M(1,1)$ Model. $x^{(1)}(k+1)=\beta_{1} x^{(1)} \beta_{2}$ is written as a basic of discrete grey model (DGM) or a discretization of the GM(1,1) model. The overall procedure to obtain all details about discrete grey models can be referred to as a full book about Grey Systems Theory written by Liu and Lin [10], which is shown step-by-step as below.

Theorem 6. Let $X^{(0)}=\left\{x^{(0)}(1), x^{(0)}(2), \ldots, x^{(0)} n\right\}$ be a nonnegative sequence and its accumulation generation $X^{(1)}=$ $\left\{x^{(1)}(1), x^{(1)}(2), \ldots, x^{(1)} n\right\}$. If $\widehat{\beta}=\left(\beta_{1}, \beta_{2}\right)^{T}$ is the parametric sequence and

$$
\begin{aligned}
& Y=\left[\begin{array}{c}
x^{(1)}(2) \\
x^{(1)}(3) \\
\vdots \\
x^{(1)}(n)
\end{array}\right], \\
& B=\left[\begin{array}{cc}
x^{(1)}(1) & 1 \\
x^{(1)}(2) & 1 \\
\vdots & \vdots \\
x^{(1)}(n-1) & 1
\end{array}\right],
\end{aligned}
$$

then the least squares estimates of the parameters of the discrete model $x^{(1)}(k+1)=\beta_{1} x^{(1)}(k)+\beta_{2}$ satisfy $\widehat{\beta}=\left(B^{T} B\right)^{-1} B^{T} Y$.

Proof. Substituting the data sequence into the grey differential equation $x^{(1)}(k+1)=\beta_{1} x^{(1)}(k)+\beta_{2}$ produces

$$
\begin{aligned}
& x^{(1)}(2)=\beta_{1} x^{(1)}(1)+\beta_{2}, \\
& x^{(1)}(3)=\beta_{1} x^{(1)}(2)+\beta_{2},
\end{aligned}
$$

$$
x^{(1)}(n)=\beta_{1} x^{(1)}(n-1)+\beta_{2} .
$$

Here is matrix $B \widehat{\beta}=Y$. For a pair of estimated values of $\beta_{1}, \beta_{2}$, using $\beta_{1} x^{(1)}(k)+\beta_{2}$ to substitute $x^{(1)}(k+1), k=$ $1,2, \ldots, n-1$, on the left-hand side leads to the error sequence $\varepsilon=Y-B \widehat{\beta}$. Assume that

$$
\begin{aligned}
S & =\varepsilon^{T} \varepsilon=(Y-B \widehat{\beta})^{T}(Y-B \widehat{\beta}) \\
& =\sum_{k=1}^{n-1}\left(x^{(1)}(k+1)-\beta_{1} x^{(1)}(k)-\beta_{2}\right)^{2} .
\end{aligned}
$$


So, the values of $\beta_{1}, \beta_{2}$ making $S$ the smallest possible satisfy

$$
\begin{aligned}
\frac{\partial S}{\partial \beta_{1}} & =-2 \sum_{k=1}^{n-1}\left(x^{(1)}(k+1)-\beta_{1} x^{(1)}(k)-\beta_{2}\right) \cdot x^{(1)}(k) \\
& =0
\end{aligned}
$$

$$
\frac{\partial S}{\partial \beta_{1}}=-2 \sum_{k=1}^{n-1}\left(x^{(1)}(k+1)-\beta_{1} x^{(1)}(k)-\beta_{2}\right)=0
$$

Solving this system of equations produces

$$
\begin{aligned}
& \beta_{1}=\frac{\sum_{k=1}^{n-1}\left(x^{(1)}(k+1)(k)\right)-(1 /(n-1)) \sum_{k=1}^{n-1}\left(x^{(1)}(k+1)\right) \sum_{k=1}^{n-1}\left(x^{(1)}(k)\right)}{\sum_{k=1}^{n-1}\left(x^{(1)}(k)\right)^{2}-(1 /(n-1)) \sum_{k=1}^{n-1}\left(x^{(1)}(k)\right)^{2}}, \\
& \beta_{2}=\frac{1}{n-1}\left[\sum_{k=1}^{n-1}\left(x^{(1)}(k+1)\right)-\beta_{1} \sum_{k=1}^{n-1}\left(x^{(1)}(k)\right)\right] .
\end{aligned}
$$

From $B \widehat{\beta}=Y$, it follows that

$$
B^{T} B \widehat{\beta}=B^{T} Y, \quad \widehat{\beta}=\left(B^{T} B\right)^{-1} B^{T} Y .
$$

However, from

$$
\begin{aligned}
& B^{T} B=\left[\begin{array}{cc}
x^{(1)}(1) & 1 \\
x^{(1)}(2) & 1 \\
\vdots & \vdots \\
x^{(1)}(n-1) & 1
\end{array}\right]^{T}\left[\begin{array}{cc}
x^{(1)}(1) & 1 \\
x^{(1)}(2) & 1 \\
\vdots & \vdots \\
x^{(1)}(n-1) & 1
\end{array}\right] \\
& =\left[\begin{array}{cc}
\sum_{k=1}^{n-1}\left(x^{(1)}(k)\right)^{2} & \sum_{k=1}^{n-1}\left(x^{(1)}(k)\right) \\
\sum_{k=1}^{n-1}\left(x^{(1)}(k)\right) & n-1
\end{array}\right] \text {, } \\
& \left(B^{T} B\right)^{-1} \\
& =\frac{1}{(n-1) \sum_{k=1}^{n-1}\left(x^{(1)}(k)\right)^{2}-\left[\sum_{k=1}^{n-1}\left(x^{(1)}(k)\right)\right]^{2}} \\
& \widehat{\beta}=\left(B^{T} B\right)^{-1} B^{T} Y=\frac{1}{(n-1) \sum_{k=1}^{n-1}\left(x^{(1)}(k)\right)^{2}-\left[\sum_{k=1}^{n-1}\left(x^{(1)}(k)\right)\right]^{2}} \\
& \times\left[\begin{array}{c}
(n-1) \sum_{k=1}^{n-1} x^{(1)}(k) x^{(1)}(k+1)-\sum_{k=1}^{n-1}\left(x^{(1)}(k)\right) \sum_{k=1}^{n-1} x^{(1)}(k+1) \\
-\sum_{k=1}^{n-1}\left(x^{(1)}(k)\right) \sum_{k=1}^{n-1} x^{(1)}(k) x^{(1)}(k+1)+\sum_{k=1}^{n-1} x^{(1)}(k+1) \sum_{k=1}^{n-1}\left(x^{(1)}(k)\right)^{2}
\end{array}\right] \\
& =\left[\begin{array}{c}
\frac{\sum_{k=1}^{n-1} x^{(1)}(k) x^{(1)}(k+1)-(1 /(n-1)) \sum_{k=1}^{n-1} x^{(1)}(k+1) \sum_{k=1}^{n-1}\left(x^{(1)}(k)\right)}{\sum_{k=1}^{n-1}\left(x^{(1)}(k)\right)^{2}-(1 /(n-1)) \sum_{k=1}^{n-1}\left(x^{(1)}(k)\right)^{2}} \\
\frac{1}{n-1} \sum_{k=1}^{n-1} x^{(1)}(k+1)-\beta_{1} \sum_{k=1}^{n-1} x^{(1)}(k)
\end{array}\right]=\left[\begin{array}{l}
\beta_{1} \\
\beta_{2}
\end{array}\right] .
\end{aligned}
$$


Theorem 7. Let $B, Y, \widehat{\beta}$ be the same as defined in Theorem 1 and $\widehat{\beta}=\left[\begin{array}{l}\beta_{1} \\ \beta_{2}\end{array}\right]=\left(B^{T} B\right)^{-1} B^{T} Y$. Then, the following hold true:

(1) If $x^{(1)}(1)=x^{(0)}(1)$, the recurrence relation is

$$
\begin{aligned}
\hat{x}^{(1)}(k+1)=\beta_{1}^{k} x^{(0)}(1)+\frac{1-\beta_{1}^{k}}{1-\beta_{1}} * \beta_{2} & \\
k & =1,2, \ldots n-1 ; \\
\text { or } \hat{x}^{(1)}(k+1) & =\beta_{1}^{k}\left(x^{(0)}(1)-\frac{\beta_{2}}{1-\beta_{1}}\right)+\frac{\beta_{2}}{1-\beta_{1}} ; \\
k & =1,2, \ldots n-1 .
\end{aligned}
$$

(2) The restored values are

$$
\begin{aligned}
\widehat{x}^{(0)}(k+1) & =\alpha^{(1)} \widehat{x}^{(1)}(k+1) \\
& =\widehat{x}^{(1)}(k+1)-\widehat{x}^{(1)}(k) ; \\
& \quad k=1,2, \ldots, n-1 .
\end{aligned}
$$

Proof. (1) Substituting the obtained $\beta_{1}, \beta_{2}$ into the discrete form produces

$$
\begin{aligned}
\widehat{x}^{(0)}(k+1)= & \beta_{1} \widehat{x}^{(1)}(k)+\beta_{2} \\
= & \beta_{1}\left(\beta_{1} \widehat{x}^{(1)}(k-1)+\beta_{2}\right)+\beta_{2}=\cdots \\
= & \beta_{1}^{k} x^{(1)}(1) \\
& +\left(\beta_{1}^{k-1}+\beta_{1}^{k-2}+\cdots+\beta_{1}+1\right) \cdot \beta_{2} .
\end{aligned}
$$

Letting $x^{(1)}(1)=x^{(0)}(1)$ leads to

$$
\widehat{x}^{(1)}(k+1)=\beta_{1}^{k} x^{(0)}(1)+\frac{1-\beta_{1}^{k}}{1-\beta_{1}} \cdot \beta_{2} .
$$

So $(2) \widehat{x}^{(1)}(k+1)-\widehat{x}^{(1)}(k)=\sum_{i=1}^{k+1} \widehat{x}^{(0)}(i)-\sum_{i=1}^{k} \widehat{x}^{(0)}(i)=\widehat{x}^{(0)}(k+$ $1)$.

2.3. ARIMA Models. The Autoregressive Integrated Moving Average (ARIMA) models for forecasting time series are essentially agnostic. The ARIMA methods are not assumable with background of any underlying economic model or structural relationships. It is assumed that past values of the series plus previous error terms contain information for the purposes of forecasting [11].

The number of times in the series must be differenced to induce the stationary of the integrated component with the $(p, d, q)(P, D, Q)$ as the following notations:

$p$ is the number of autoregressive terms.

$q$ is the number of moving average terms.

$d$ is the number of times a series.

$P$ is the number of seasonal autoregressive components.
$Q$ is the number of seasonal moving average terms.

$D$ is the number of seasonal differences.

This may be written as

$$
\emptyset(B) \Phi(B) \nabla^{d} \nabla_{s}^{D} Y_{t}=\theta(B) \Theta(B) a_{t},
$$

where $X_{t}=\nabla^{d} \nabla_{s}^{D} Y_{t}$ is a stationary series, $\nabla^{d}=(1-B)^{d}$ represents the number of regular differences, $\nabla_{s}^{D}=\left(1-B^{s}\right)^{D}$ represents the number of seasonal differences required to induce stationarity in $Y_{t}, \mathbf{s}$ is the seasonal span (hence for quarterly data $s=4$ and for monthly data $s=12), B$ is the backshift operator (such that $B^{0} X_{t}=X_{t}, B^{1} X_{t}=$ $\left.X_{t-1}, B^{2} X_{t}=X_{t-2}, \ldots\right)$, and $\theta(B)=1+\theta_{1} B+\theta_{2} B^{2}+\cdots+\theta_{q} B^{q}$ is a $q$-order polynomial in the backshift operator:

$$
\begin{aligned}
& \emptyset(B)=1-\emptyset_{1} B-\emptyset_{2} B^{2}-\cdots-\emptyset_{p} B^{p}, \\
& \Phi(B)=1-\Phi_{1 s} B^{1 s}-\Phi_{2 s} B^{2 s}-\cdots-\Phi_{P s} B^{P s}, \\
& \Theta(B)=1+\Theta_{1 s} B^{1 s}+\Theta_{2 s} B^{2 s}+\cdots+\Theta_{Q s} B^{Q s} .
\end{aligned}
$$

Following are some common models with their parameters which can help make the forecasting process accurate.

$\operatorname{ARIMA}(0,1,0)$ denotes random walk:

$$
\widehat{Y}(t)-Y(t-1)=\mu,
$$

the random-walk-with-growth model to the time series $Y$.

$\operatorname{ARIMA}(1,1,0)$ denotes differenced first-order autoregressive model as

$$
\widehat{Y}(t)-(Y-1)=\mu+\emptyset(Y(t-1)-Y(t-2))
$$

can be rearranged to

$$
\widehat{Y}(t)=\mu+Y(t-1)+\emptyset(Y(t-1)-Y(t-2)) .
$$

$\operatorname{ARIMA}(0,1,1)$ without constant means simple exponential smoothing:

$$
\widehat{Y}(t)=(Y-1)-\theta e(t-1),
$$

where $e(t-1)$ denotes the error at period $t-1$. Note that this resembles the prediction equation for the $\operatorname{ARIMA}(1,1,0)$ model.

$\operatorname{ARIMA}(0,2,1)$ or $(0,2,2)$ without constant stands for linear exponential smoothing:

$$
\begin{aligned}
\widehat{Y}(t) & -2 Y(t-1)+Y(t-2) \\
= & -\theta_{1} e(t-1)-\theta_{2} e(t-2) .
\end{aligned}
$$

For obtaining procedures, Hanke and Wichern [12] and Etuk [13] have described and explained in detail about the ARIMA models.

2.4. Previous Studies. In recent years, the grey system theory and ARIMA models have been widely used to forecast in various fields and demonstrated satisfactory results. ARIMA 
models have proven themselves to be relatively robust especially when generating short-run inflation forecasts. ARIMA models frequently outperform more sophisticated structural models in terms of short-run forecasting ability (see $[14,15]$ ). Therefore, the ARIMA forecasting technique outlined in this paper will not only provide a benchmark by which other forecasting techniques may be appraised but also provide an input into forecasting in its own right. Whereas, grey model was used to predict the manpower of undergraduate educational systems in Vietnam (see [16]). Tongyuan and Yue [17] had applied grey model to predict the urban traffic accident in China; Lin, et al. [18] had presented the adaptive and high precision grey forecasting model to predict the stock index in Taiwan; Zhu [19] had used the composite grey BP neural network forecasting model for motor vehicle fatality risk in China; Zhou, et al. [20] had used a trigonometric grey prediction approach to forecasting electricity demand; Lu [21] had used the grey system theory to analyze and forecast the road traffic safety improvement in Netherlands; Mao and Sun [7] had applied the Grey-Markov model in forecasting fire accidents in China; Wu and Chen [22] had used a prediction model using the grey model $\operatorname{GMC}(1, n)$ combined with the grey relational analysis to predict the internet access population in Taiwan.

\section{Data Source and Description}

We obtained the data of the indexes related to inflation of Vietnam from 2005 to November, 2013. The database of GSO-VN provides details of Consumer Price Index (CPI), Raw Materials Price (RMP), Gold Price (GP), Dollar Price (DP), and so forth. We retrieved the data for the year-on-year indexes which are suitable for this paper's purposes.

The data included in the analysis have main characteristics: a correlation with inflation (not high but relative) and timeliness, that is, an earlier release than the inflation data. These characteristics can help to improve the accuracy of inflation forecasts. In practice, we obtain the dataset containing three of variables (the total CPI, RWP with main components: energy, services, goods, food, and beverages, and Gold Price, GP). In the context of Vietnam, three of the groups relate to consumer prices directly and capture raw material, energy, and manufacturing and nonmanufacturing prices at various stages of the pricing chain. The remaining group includes Gold Price data, which aim to capture the general economic conditions that can eventually affect the Vietnamese inflation.

More precisely, the first group of variables in our dataset includes energy, services, goods, food, and beverages, Price of Raw Materials (RMP). These data are sample data monthly frequency and are published every month (at the end of each month) on the official website of GSO-VN. Figure 3 shows that there is indeed a relatively high degree of correlation between the average year-on-year growth rate of RMP series and the year-on-year growth rate of total CPI. This is a desirable feature for data which are employed for forecasting inflation.

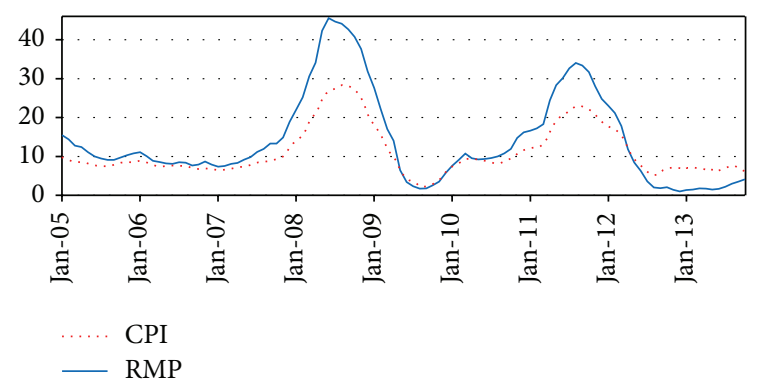

Figure 3: Raw Material Prices (\%). Note: this figure shows the evolution of the year-on-year growth rates of overall CPI and of the average of the 108 Raw Material Price (RMP) series. All of the series are standardized.

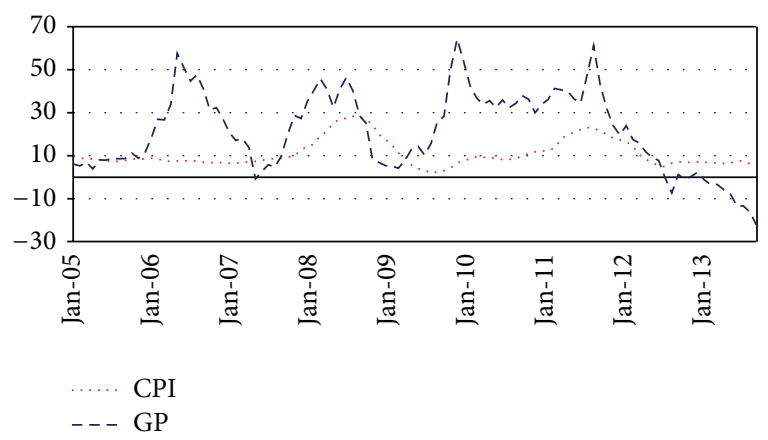

FIGURE 4: Gold Prices (\%). Note: this figure shows the evolution of the year-on-year growth rates of overall CPI and of the average of the 108 Gold Price (GP) series. All of the series are standardized.

With regard to the eight-year sequence shown in Figure 4 as yearly differences, the GP does not appear to have a strong contemporaneous correlation with the total CPI. Overall, the evidence on the correlation of the GP data with total inflation does not point to a consistent direction among the various variables. However, we include these data as they are the timeliest data in the current data set.

Finally, because this paper focuses on the forecasts of CPI (total and components), the data set includes 2 CPI series, that is, the total CPI plus its components: energy, food and beverages, goods and services (RMP), and Gold Price (CP). By assessing the effects of the remaining groups of variables (RMP and GP data) on the forecast of each individual CPI component, we shed light on the underlying forces driving an improvement in the forecast accuracy of the total CPI.

The tables below and the figures illustrate the descriptive data variables. They show (in Tables 1, 2, and 3) the normality and white noise tests results of CPI, RMP, and GP, respectively. They clearly show us the $p$ value less than 0.05 , except the first parameter of GP since the eight-year period of GP fluctuates wildly (described in Figure 4). Moreover, the descriptive analyses also show the lag summary of variables in this study, the autocorrelogram and partial autocorrelogram which are shown in Figures 5, 6, and 7 in detail. 

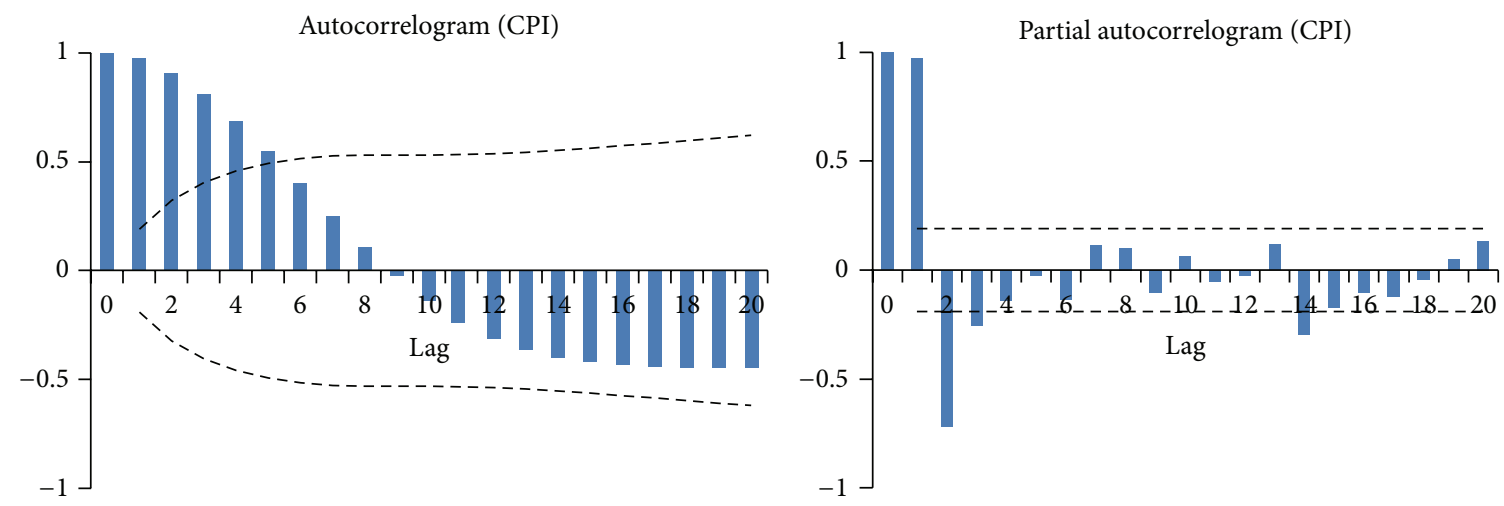

FIGURE 5: The autocorrelogram and partial autocorrelogram of CPI after descriptive analysis.
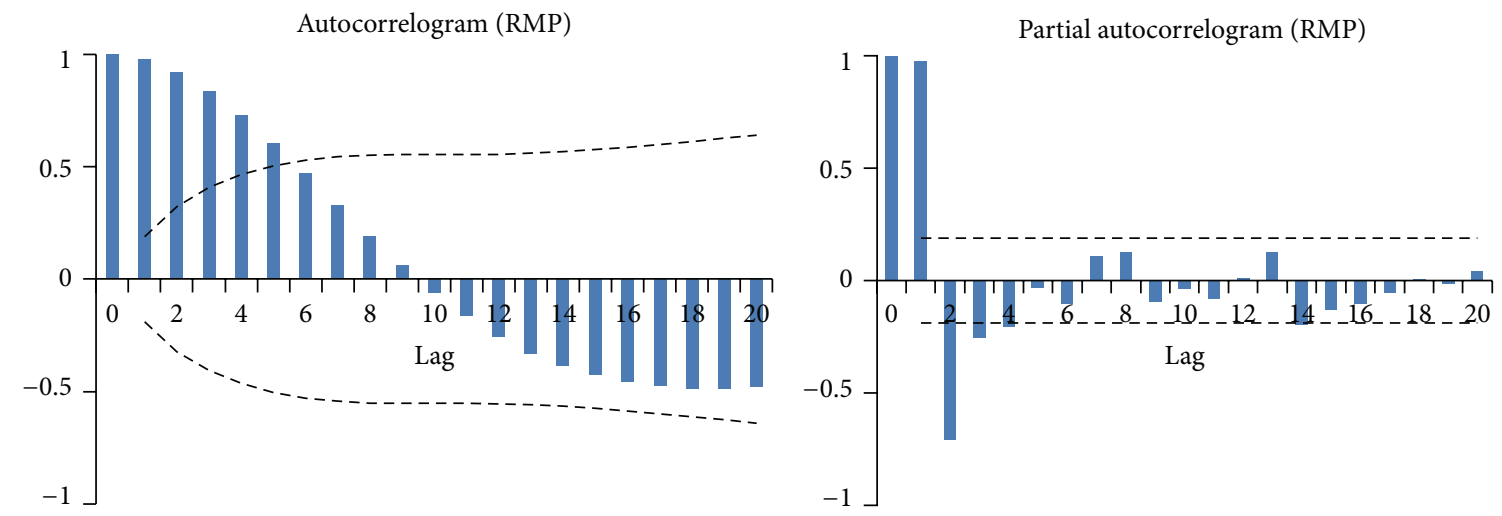

FIGURE 6: The autocorrelogram and partial autocorrelogram of RMP after descriptive analysis.

TABLE 1: Normality and white noise tests (CPI).

\begin{tabular}{lccc}
\hline Statistic & DF & Value & $p$ value \\
\hline Jarque-Bera & 2 & 30.988 & $<0.0001$ \\
Box-Pierce & 6 & 359.358 & $<0.0001$ \\
Ljung-Box & 6 & 375.472 & $<0.0001$ \\
McLeod-Li & 6 & 348.637 & $<0.0001$ \\
\hline Box-Pierce & 12 & 385.983 & $<0.0001$ \\
Ljung-Box & 12 & 405.456 & $<0.0001$ \\
McLeod-Li & 12 & 372.297 & $<0.0001$ \\
\hline
\end{tabular}

TABLE 2: Normality and white noise tests (RMP).

\begin{tabular}{lccc}
\hline Statistic & DF & Value & $p$ value \\
\hline Jarque-Bera & 2 & 25.712 & $<0.0001$ \\
Box-Pierce & 6 & 386.059 & $<0.0001$ \\
Ljung-Box & 6 & 403.808 & $<0.0001$ \\
McLeod-Li & 6 & 353.985 & $<0.0001$ \\
\hline Box-Pierce & 12 & 412.161 & $<0.0001$ \\
Ljung-Box & 12 & 432.860 & $<0.0001$ \\
McLeod-Li & 12 & 373.363 & $<0.0001$ \\
\hline
\end{tabular}

\section{Procedure and Result Evaluation}

In this section, we begin by explaining the process of forecasting exercises. We then present models and describe
TABLE 3: Normality and white noise tests (GP).

\begin{tabular}{lccc}
\hline Statistic & DF & Value & $p$ value \\
\hline Jarque-Bera & 2 & 2.037 & 0.361 \\
Box-Pierce & 6 & 268.271 & $<0.0001$ \\
Ljung-Box & 6 & 279.880 & $<0.0001$ \\
McLeod-Li & 6 & 156.511 & $<0.0001$ \\
\hline Box-Pierce & 12 & 277.923 & $<0.0001$ \\
Ljung-Box & 12 & 290.563 & $<0.0001$ \\
McLeod-Li & 12 & 187.669 & $<0.0001$ \\
\hline
\end{tabular}

the process evaluating the forecast performances. Finally, we present the results. In order to determine whether high frequency data can improve the inflation forecast accuracy, we compare the following models.

(i) ARIMA. With the process of forecasting CPI and RMP, we administered the model parameters at $p=0 ; d=1 ; q=1$ and $P=0 ; D=1 ; Q=1$ with $s=12$ (which means ARIMA model in simple exponential smoothing with growth). Then, for the forecasting of GP variables, model parameters are at $p=0 ; d=2 ; q=2$ and $P=0 ; D=0 ; Q=0$ with $s=0$; this is known as linear exponential smoothing.

(ii) $\operatorname{GM}(1,1)$. Consider $a=0.122699 ; b=6.999603$, and the result of $\left(1-e^{a}\right)\left(x^{(0)}(1)-b / a\right)=6.958098$ of the applied calculation for CPI. 

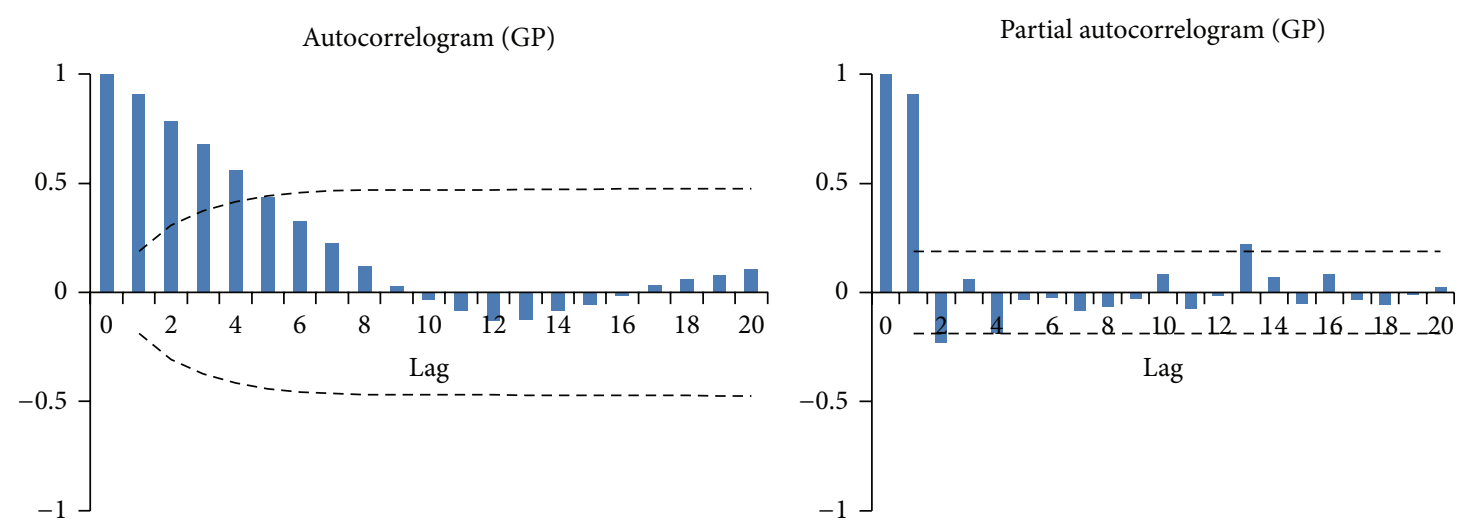

FIGURE 7: The autocorrelogram and partial autocorrelogram of GP after descriptive analysis.

The results of parameters relating to RMP are $a=$ $-0.168843, b=0.862905$, and $\left(1-e^{a}\right)\left(x^{(0)}(1)-b / a\right)=$ 1.028581 .

Therefore, $a=-0.208730, b=-4.046203$, and $(1-$ $\left.e^{a}\right)\left(x^{(0)}(1)-b / a\right)=-3.877893$ are related to the calculation of GP.

(iii) VERHULST. There is CPI with its parameters of Verhulst in calculation: $a=0.226108, b=0.030807$, and $\widehat{\mathbf{x}}(\mathbf{k}+\mathbf{1})=$ $\mathbf{a x}{ }^{(\mathbf{1})}(\mathbf{0}) /\left(\mathbf{b x}{ }^{(\mathbf{1})}(\mathbf{0})+\left(\mathbf{a}-\mathbf{b} \mathbf{x}^{(\mathbf{1})}(\mathbf{0})\right) \mathbf{e}^{\mathbf{a k}}\right)$ (mentioned in Section 2) in which $a x^{(1)}(0)=1.587278, a-b x^{(1)}(0)=0.009845$, and $b x^{(1)}(0)=0.216263$.

For RMP's, $a=-0.105978 ; b=0.015999$; and equation with $a x^{(1)}(0)=-0.160026 ; a-b x^{(1)}(0)=-0.130136$; and $b x^{(1)}(0)=0.024159$.

For GP's, $a=-0.527312 ; b=0.021474$; and equation with $a x^{(1)}(0)=0.632775 ; a-b x^{(1)}(0)=-0.501543$; and $b x^{(1)}(0)=$ -0.025769 .

(iv) $\operatorname{DGM}(1,1)$ and $\operatorname{DGM}(2,1)$. CPI calculation is with the following parameters: $\beta_{1}=0.98797 ; \beta_{2}=6.972392$, so $x^{(0)}(1)\left(\beta_{1}-1\right)+\beta_{2}=6.887939$.

With the same process, we have for RMPs $\beta_{1}=1.183242$; $\beta_{2}=0.95365$, so $x^{(0)}(1)\left(\beta_{1}-1\right)+\beta_{2}=1.230346$.

Finally, calculation of GP is as follows: $\beta_{1}=1.230543$; $\beta_{2}=-4.597065$, so $x^{(0)}(1)\left(\beta_{1}-1\right)+\beta_{2}=-4.873716$.

In the description section, we mentioned the eight-year dataset; however, 10 months of 2013 data are taken into account for forecasting process. After that, the output will be next 04 years of variables (CPI, RMP, and GP). The data under analysis are never revised. There, we see that the information enters into the estimation gradually. The quality of the information content of each release affects the accuracy of the forecast. Our models can be evaluated in any given month. Table 4 shows in detail the available results of this process (actual values and the forecast's by the given models.)

Moreover, to have a better view of the values after calculation, we use Figures 8 and 9 . These figues are just doing the job of summarizing Table 4, results from the applied models are obvious. We can easily recognize that the models GM(1,1) and DGM $(1,1)$ have a very high correlation. Besides,

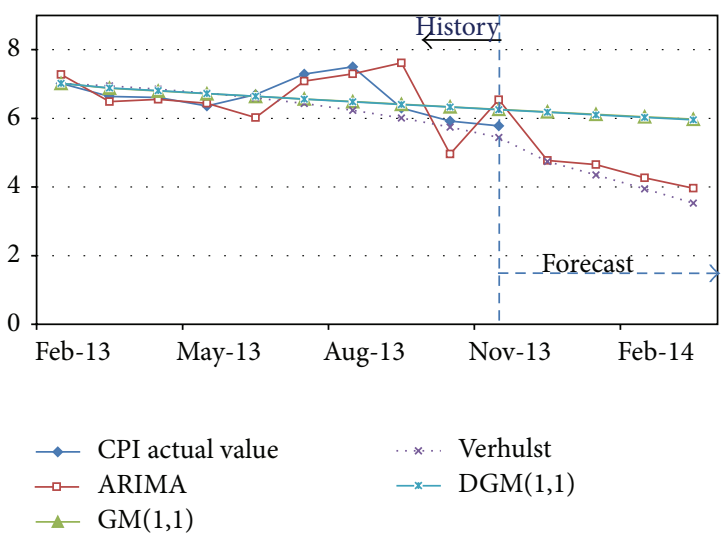

FIGURE 8: Actual and forecast CPI values for 04 models. Note: the $\operatorname{DGM}(2,1)$ values are not included.

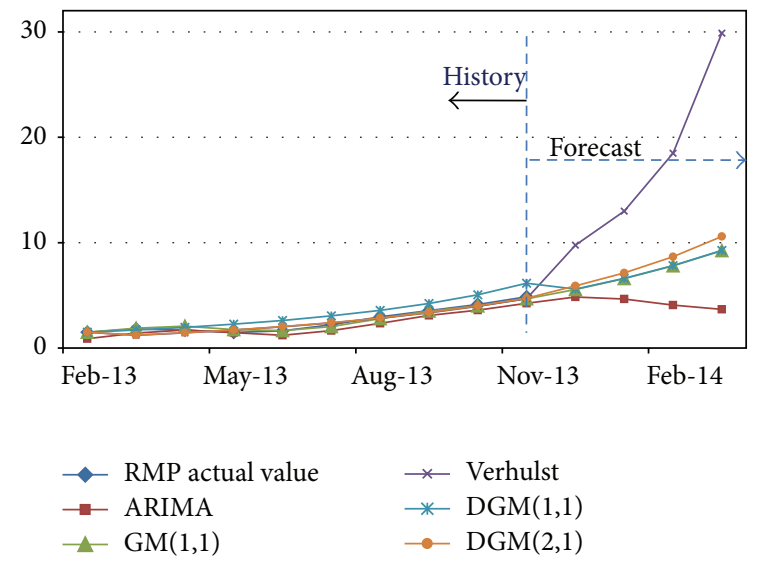

Figure 9: Actual and forecast RMP values for 05 models.

these models prove their excellent ability in forecasting when their values are on the same trend with the actual values.

In particular, Figure 9 shows us the accuracy of the values in which they are coming closer to each other with a relative high correlation.

Differences in Results of Proposed Forecasting Models. Firstly, we set up the null hypothesis then we employ the Friedman 


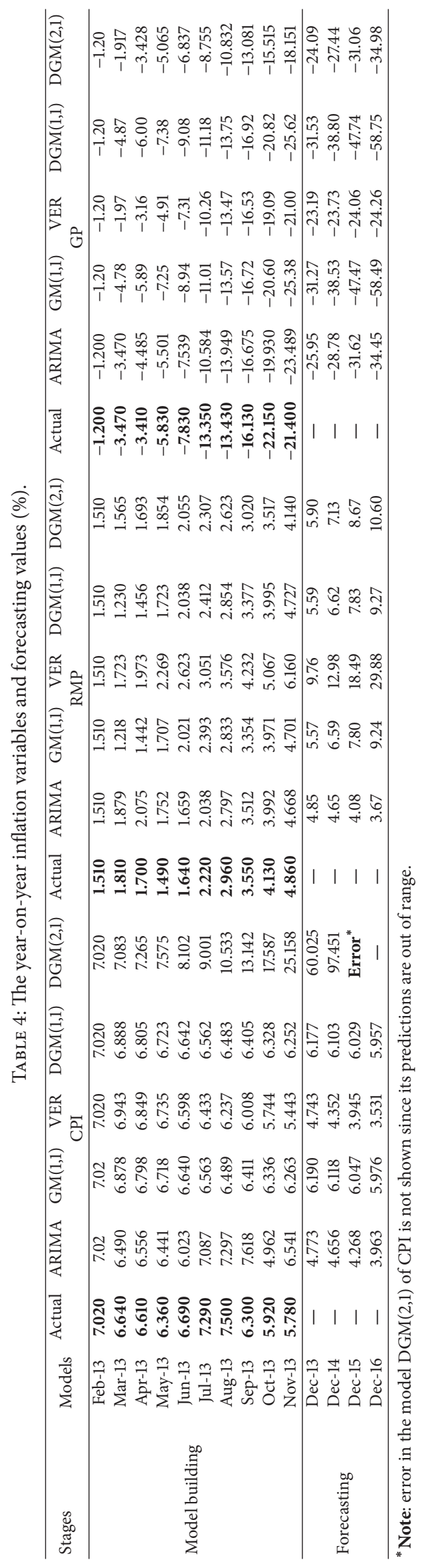


TABLE 5: Descriptive statistics of forecasting results in the CPI section.

\begin{tabular}{|c|c|c|c|c|c|c|}
\hline & $N$ & Mean & Standard deviation & Minimum & Maximum & Mean rank \\
\hline ARIMA & 10 & 6.6035 & .74493 & 4.96 & 7.62 & 2.40 \\
\hline $\mathrm{GM}(1,1)$ & 10 & 6.6116 & .24489 & 6.26 & 7.02 & 2.80 \\
\hline VER & 10 & 6.4010 & .53331 & 5.44 & 7.02 & 2.30 \\
\hline $\operatorname{DGM}(1,1)$ & 10 & 6.6108 & .25063 & 6.25 & 7.02 & 2.70 \\
\hline $\operatorname{DGM}(2,1)$ & 10 & 11.2466 & 5.93758 & 7.02 & 25.16 & 4.80 \\
\hline
\end{tabular}

TABLE 6: Test statistics ${ }^{\mathrm{a}}$.

\begin{tabular}{lc}
\hline$N$ & 10 \\
\hline Chi-square & 18.756 \\
df & 4 \\
Asymp. Sig. & .001 \\
\hline
\end{tabular}

${ }^{a}$ Friedman test.

TABLE 7: Wilcoxon test results.

\begin{tabular}{lllcc}
\hline & & $N$ & $Z$ & Sig. (2-tailed) \\
\hline $\operatorname{DGM}(2,1)$ & Negative ranks & $9^{\mathrm{a}}$ & & \\
against other & Positive ranks & $0^{\mathrm{b}}$ & 2.67 & 0.008 \\
models & Ties & $1^{\mathrm{c}}$ & & \\
& Total & 10 & & \\
\hline
\end{tabular}

${ }^{\mathrm{a}}$ Others $<\operatorname{DGM}(2,1),{ }^{\mathrm{b}}$ others $>\operatorname{DGM}(2,1)$, and ${ }^{\mathrm{c}}$ others = DGM $(2,1)$.

test to see any differences among the forecasting models. After that, a post hoc test, Wilcoxon, is used to see how these differences are.

$H_{0}$ : There are no differences in results of forecasting models used in this study.

Here is the result of Friedman test using forecasting results in the CPI section.

From Table 5, the means of ARIMA, GM(1,1), VERHULST, and DGM $(1,1)$ are much the same while DGM(2,1)'s is the highest one. This also happens in the mean rank column.

The Friedman test result is shown in Table 6, which is $\left(\chi^{2}=18.76, \mathrm{df}=4, p=0.001\right) ; p<0.05$. That means the null hypothesis is rejected; that is, there are significant differences among the results of forecasting.

To further analysis, the post hoc test, Wilcoxon, is employed to find what and how these differences are (see Table 7). In this section, we just summarize the only differences between $\operatorname{DGM}(2,1)$ and the other models because we see the result $(Z=2.67 ; p=0.008 ; p<0.05)$. In detail, 9 out of 10 digits in the forecasting results of $\operatorname{DGM}(2,1)$ are larger than the others. Thus, there is significant difference between $\operatorname{DGM}(2,1)$ and the others in the forecasting results.

With the same process, we also see that there are significant differences among the results of forecasting RMP at the level of $\left(\chi^{2}=17.24, \mathrm{df}=4, p=0.002\right)$. In addition, these differences are among GM(1,1) versus Verhulst and DGM(1,1) versus Verhulst at the difference level of $(Z=2.67, p=0.008$, and $p<0.05$ ).
Finally, the testing results of Gold Price see the significant difference $\left(\chi^{2}=32.62, \mathrm{df}=4\right.$, and $\left.p=0.000\right)$. Furthermore, more complicated differences among the models after we test post hoc which are Verhulst versus others, with $p$ value around 0.008 to 0.038 and $\operatorname{DGM}(2,1)$ versus others.

In short, to answer the research question 1, there exist the significant differences among forecasting models applied in this study. These differences are among $\operatorname{DGM}(2,1)$ and Verhulst versus the other models. Thus, the improved model $\operatorname{DGM}(1,1)$ performed very well in this case; at least, it has a close correlation with $\mathrm{GM}(1,1)$ and the others, except Verhulst and DGM(2,1), half answering research question 2.

Accurate Inspection Analysis of Forecasting Ability. So far, numerous methods exist for judging forecasting model accuracy, and no single recognized inspection method exists for forecasting ability $[23,24]$. Mean Absolute Percentage Error (MAPE) is often used to measure forecasting accuracy. In the book of Stevenson [25], it is stated clearly MAPE is the average absolute percent error which measures of accuracy in a fitted time series value in statistics, specifically trending [26]:

$$
\begin{array}{r}
\text { MAPE }=\frac{1}{n} \sum \frac{\mid \text { Actual }- \text { Forecast } \mid}{\text { Actual }} \times 100 ; \\
n \text { Forecasting number of step. }
\end{array}
$$

The parameters of MAPE stating the forecasting ability are as follows:

(i) MAPE $<10 \%$ says "excellent."

(ii) $10 \%<$ MAPE < 20\% "good."

(iii) $20 \%<$ MAPE < 50\% "reasonable."

(iv) MAPE > 50\% "poor."

Secondly, the MSE means Squared Forecast Error and can be decomposed as

$$
\mathrm{MSE}=\frac{1}{h+1} \sum_{t=s}^{s+h}\left(\widehat{x}_{t-1}(1)-x_{t}\right)^{2}
$$

The next step will be the development of MSE to its root one (RMSE). The RMSE (Root Squared Forecast Error) depends on the scale of the dependent variable. It should be used as relative measure to compare forecasts for the same series across different models. The smaller the error, the better 
TABLE 8: Evaluating models with CPI forecasting errors.

\begin{tabular}{lccccc}
\hline Models & ARIMA & GM $(1,1)$ & VERHULST & DGM $(1,1)$ & DGM $(2,1)$ \\
\hline MAPE & $6.94 \%$ & $5.50 \%$ & $6.25 \%$ & $5.50 \%$ & 0.220 \\
MSE & 0.379 & 0.219 & 0.286 & 0.469 & 57.466 \\
RMSE & 0.616 & 0.468 & 0.535 & 0.358 & 7.581 \\
MAD & 0.440 & 0.358 & 0.393 & Good & Excellent \\
Evaluation & Good & Excellent & & & Poor \\
\hline
\end{tabular}

TABLE 9: Evaluating models with RMP forecasting errors.

\begin{tabular}{|c|c|c|c|c|c|}
\hline Models & ARIMA & $\mathrm{GM}(1,1)$ & VERHULST & $\operatorname{DGM}(1,1)$ & $\operatorname{DGM}(2,1)$ \\
\hline MAPE & $6.13 \%$ & $12.30 \%$ & $19.09 \%$ & $12.00 \%$ & $12.49 \%$ \\
\hline MSE & 0.033 & 0.074 & 0.576 & 0.072 & 0.166 \\
\hline RMSE & 0.182 & 0.273 & 0.759 & 0.269 & 0.408 \\
\hline MAD & 0.144 & 0.226 & 0.649 & 0.219 & 0.332 \\
\hline Evaluation & Excellent & Good & Poor & Good & Reasonable \\
\hline
\end{tabular}

the forecasting ability of this model, according to the RMSE criterion. Therefore,

$$
\mathrm{RMSE}=\sqrt{\frac{1}{h+1} \sum_{t=s}^{s+h}\left(\widehat{x}_{t-1}(1)-x_{t}\right)^{2}}
$$

Finally, to evaluate the ability of our available models used in this research, we apply Mean Absolute Deviation (MAD). $\mathrm{MAD}$ is an average of the difference between the forecast and the actual values. Following is the formula:

$$
\operatorname{MAD}=\frac{\sum_{i=1}^{n}\left|e_{i}\right|}{n} .
$$

The smaller/lower the value of MAD, the more accurate the forecast. One benefit of MAD is to compare the accuracy of several different forecasting techniques.

Table 8 summarizes the errors by using MAPE, MSE, RMSE, and MAD to evaluate the ability of forecasting models. Those models used in this research are good ones and they prove that ability. The process and procedure to calculate out these values are mentioned above. It is obvious that $\operatorname{GM}(1,1)$ and $\operatorname{DGM}(1,1)$ are excellent to forecast the CPI (see Table 4) when their MAPEs are only 5.5\% for the whole process. Moreover, the MSE, RMSE, and MAD are at the lowest (compared with other models). ARIMA also shows its good ability in handling the job of forecasting with MAPE at $6.94 \%$ and $0.379,0.616$, and 0.440 for MSE, RMSE, and MAD, respectively. DGM, however, does not prove much in the Vietnamese CPI forecasting when its errors in prediction are relatively high. In short, Vietnamese CPI should be forecasted by using $\operatorname{GM}(1,1)$ and $\operatorname{DGM}(1,1)$ for best results and accuracy.

With the same method, Table 9 shows in detail the ability to forecast of the available models. This time, ARIMA proves it as an outstanding method when their parameters of MAPE, MSE, RMSE, and MAD are really low. In the mean time, $\operatorname{GM}(1,1)$ and $\operatorname{DGM}(1,1)$ are much the same with each other at $12.3 \%$ and $12 \%$, respectively, for MAPE. $\operatorname{DGM}(2,1)$ and Verhulst are not chosen in this area because their performance for forecasting Vietnamese RMP (see Table 4) is not well performed. In conclusion, ARIMA should be used to give prediction of Vietnamese RMP.

Finally, GP forecasting errors of applied models are mentioned in Table 10. It is clear to see the "excellent" ARIMA evaluation to be chosen in forecasting GP (see Table 4). $\mathrm{GM}(1,1)$ is rated "good" when Verhulst and $\operatorname{DGM}(1,1)$ are "reasonable." Once again, DGM(2,1) has "poor" forecasting (compared with others).

In summary, the research question 2 is fully answered after this section. The $\operatorname{DGM}(1,1)$ performed persuadably to be chosen with $\mathrm{GM}(1,1)$ in the CPI forecasting; moreover, it also has a moderate to good results in the other two (RMP and Gold Price). On the other hand, $\operatorname{DGM}(2,1)$ did not do well, when there are significant differences of this model with others, and the error criteria testing is high.

\section{Suggestions and Conclusions}

In this study, a wide range of data was used to analyze and predict inflation in developing countries, and it has come to the answers for 4 research questions which are mentioned in the previous sections. By this study, the authors would like to contribute and promote methods to find and to control the inflation in developing countries in which Vietnam is a typical example with the adopted data and variety of Vietnamese circumstances.

In the near future time, synchronous measures are to be implemented to regulate the macroeconomy. Following that, executive prudent monetary policy is doing jobs flexibly in accordance with market changes and interest rates, in order to achieve stable credit growth and to promote economic growth. Policy makers continue the implementation mechanisms in operating Gold Prices which are abreast of market demand and gold supply, so as not to make "shocks occurring mutations" in Gold Price (GP) (as the statistics in this study). Using tools to control quotas and tariffs is to regulate export and import activities items. This action can control price fluctuations of some components: energy, services, goods, 
TABLE 10: Evaluating models with GP forecasting errors.

\begin{tabular}{lccccc}
\hline Models & ARIMA & GM(1,1) & VERHULST & DGM $(1,1)$ & DGM(2,1) \\
\hline MAPE & $8.70 \%$ & $15.05 \%$ & $16.07 \%$ & $15.59 \%$ & 3.765 \\
MSE & 1.886 & 3.520 & 2.266 & 1.940 & 9.572 \\
RMSE & 1.373 & 1.876 & 1.505 & 1.562 & 3.094 \\
MAD & 0.983 & 1.492 & 1.018 & 2.346 \\
Evaluation & Excellent & Good & Reasonable & Reasonable \\
\hline
\end{tabular}

food, and beverages. Moreover, government needs to store the mentioned items. This work is done to have an on-time intervention to Vietnamese market during disaster or high prices in the world market. Inspection, market management, and distribution system are well proceeded to avoid speculation and pushing up prices of a certain organization and individual.

Forecasting inflation should be focused with care. By this study, we would contribute the trustworthy forecasting results of available models. As mentioned previously, $\operatorname{GM}(1,1)$ and $\operatorname{DGM}(1,1)$ are chosen for doing the job of forecasting CPI due to their great performance in this area of the research. RMP and GP should be forecasted by ARIMA model. Thus, this answers the research questions 3 and 4 which are the results of Vietnamese inflation; we should see Table 4, the columns of GM $(1,1)$ and DGM(1,1) for CPI and ARIMA for RMP and GP.

Inflation on one side affects the present economies; on the other hand, it has significant impacts on the society. During the period of integration into the world economy, Vietnam is under enormous pressure from inflation, so the government has to take certain measures to curb inflation. Through each measure and model, this study hopes to contribute to inflation forecasting to promote the general effect to stabilize the economy and curb inflation. For policy makers, they can refer to general effects to promote stable economic situation, curb inflation, and sustainable development in the future. The future directions can also be suggested for including or avoiding different methodologies in this completely integrated model.

\section{Websites}

General Statistics Office of Vietnam is at http://www.gso.gov .vn/default_en.aspx?tabid=491. Vietnam Report is at http:// vietnamreport.net/vn/.

\section{Conflict of Interests}

The authors declare that there is no conflict of interests regarding the publication of this paper.

\section{References}

[1] A. K. Tiwari and M. Mutascu, "Economic growth and FDI in Asia: a panel-data approach," Economic Analysis and Policy, vol. 41, no. 2, pp. 173-187, 2011.

[2] F. A. Hayek, Economic Freedom and Representative Government, Wincott Foundation, 1973.
[3] C. R. Marques, P. D. Neves, and L. M. Sarmento, "Evaluating core inflation indicators," Economic Modelling, vol. 20, no. 4, pp. 765-775, 2003.

[4] W. A. de Wet, "Thinking like a Governor: central banking under an inflation target," 2003, http://hdl.handle.net/2263/4085.

[5] M. Modugno, "Now-casting inflation using high frequency data," International Journal of Forecasting, vol. 29, no. 4, pp. 664675, 2013.

[6] J. L. Deng, "Introduction to grey system theory," The Journal of Grey System, vol. 1, no. 1, pp. 1-24, 1989.

[7] Z.-L. Mao and J.-H. Sun, "Application of Grey-Markov model in forecasting fire accidents," Procedia Engineering, vol. 11, pp. 314-318, 2011.

[8] P. Tseng, F. Lin, and C. Feng, "The analysis of human and vehicle factors for Taiwan freeway traffic accidents," Journal of the Eastern Asia Society for Transportation Studies, vol. 5, pp. 2470-2482, 2003.

[9] C. N. Wang, N. T. Nguyen, and T. T. Tran, "Integrated DEA models and grey system theory to evaluate past-to-future performance: a case of Indian electricity industry," The Scientific World Journal, vol. 2015, Article ID 638710, 17 pages, 2015.

[10] S. F. Liu and Y. Lin, Grey Sytems-Theory and Applications, Springer, Chennai, India, 2010.

[11] A. Meyler, G. Kenny, and T. Quinn, Forecasting Irish Inflation Using ARIMA Models, Technical Paper Series No. 3/RT/98, Central Bank and Financial Services Authority of Ireland, 1998.

[12] J. E. Hanke and D. W. Wichern, Business Forecasting, Pearson, Prentice-Hall, Englewood Cliffs, NJ, USA, 8th edition, 2005.

[13] E. H. Etuk, "A seasonal ARIMA model for daily Nigerian NairaUS Dollar exchange rates," Asian Journal of Empirical Research, vol. 2, no. 6, pp. 219-227, 2012.

[14] D. Stockton and J. Glassman, "An evaluation of the forecast performance of alternative models of inflation," Review of Economics and Statistics, vol. 69, no. 1, pp. 108-117, 1987.

[15] R. B. Litterman, "Forecasting with Bayesian vector autoregressions: five years of experience," Journal of Business \& Economic Statistics, vol. 4, no. 1, pp. 25-38, 1986.

[16] C. N. Wang and N. T. Nguyen, "Forecasting the manpower requirement in Vietnamese tertiary institutions," Asian Journal of Empirical Research, vol. 3, no. 5, pp. 563-575, 2013.

[17] H. Tongyuan and W. Yue, Forecasting Model of Urban Traffic Accidents Based on Grey Model-GM $(1,1)$, Institute of Computer, Chongqing Institute of Technology, 2007.

[18] Y.-H. Lin, P.-C. Lee, and T.-P. Chang, "Adaptive and highprecision grey forecasting model," Expert Systems with Applications, vol. 36, no. 6, pp. 9658-9662, 2009.

[19] X. Zhu, "Application of composite grey BP neural network forecasting model to motor vehicle fatality risk," in Proceedings of the 2nd International Conference on Computer Modeling and Simulation, pp. 236-240, 2010. 
[20] P. Zhou, B. W. Ang, and K. L. Poh, "A trigonometric grey prediction approach to forecasting electricity demand," Energy, vol. 31, no. 14, pp. 2839-2847, 2006.

[21] M. Lu, Analysis and Forecast of Road Traffic Safety Improvement in Netherlands, ARS Traffic and Transport Technology, 2007.

[22] W.-Y. Wu and S.-P. Chen, "A prediction method using the grey model GMC $(1, n)$ combined with the grey relational analysis: a case study on Internet access population forecast," Applied Mathematics and Computation, vol. 169, no. 1, pp. 198-217, 2005.

[23] N. T. Nguyen, T. T. Tran, C. N. Wang, and N. T. Nguyen, "Optimization of strategic alliances by integrating DEA and grey model," Journal of Grey System, vol. 27, no. 1, pp. 38-56, 2015.

[24] T. T. Tran, L. W. Wang, and N. T. Nguyen, "An empirical study of hybrid DEA and grey system theory on analyzing performance: a case from Indian mining industry," Journal of Applied Mathematics, vol. 2015, Article ID 395360, 15 pages, 2015.

[25] J. W. Stevenson, Operations Management, McGraw-Hill, 10th edition, 2009.

[26] L. W. Wang, T. Tran, and N. T. Nguyen, "An analysis of manpower in Vietnamese undergraduate educational system," International Journal of Economics, Business and Finance, vol. 1, no. 1, pp. 398-408, 2013. 


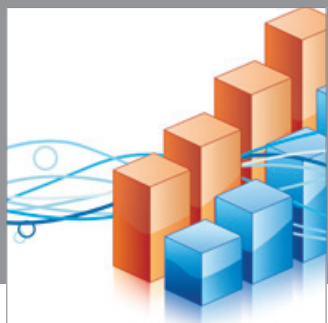

Advances in

Operations Research

mansans

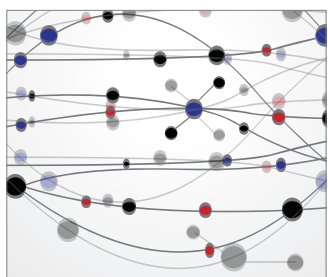

The Scientific World Journal
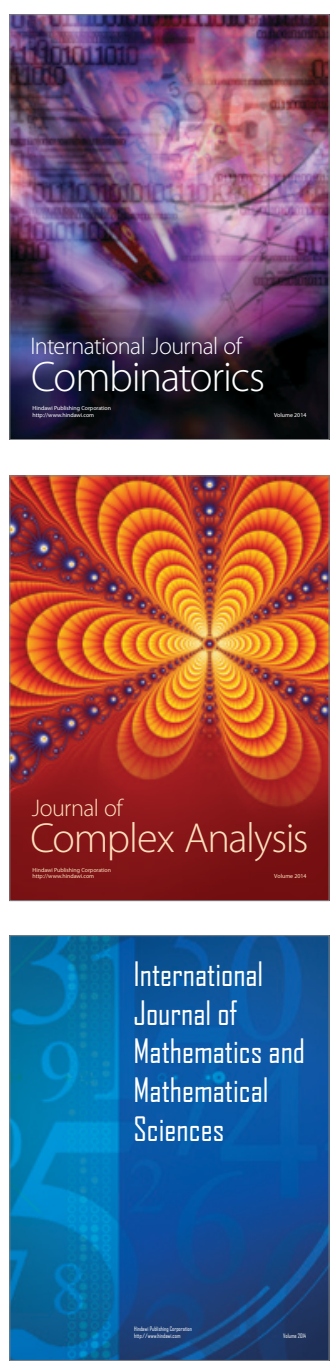
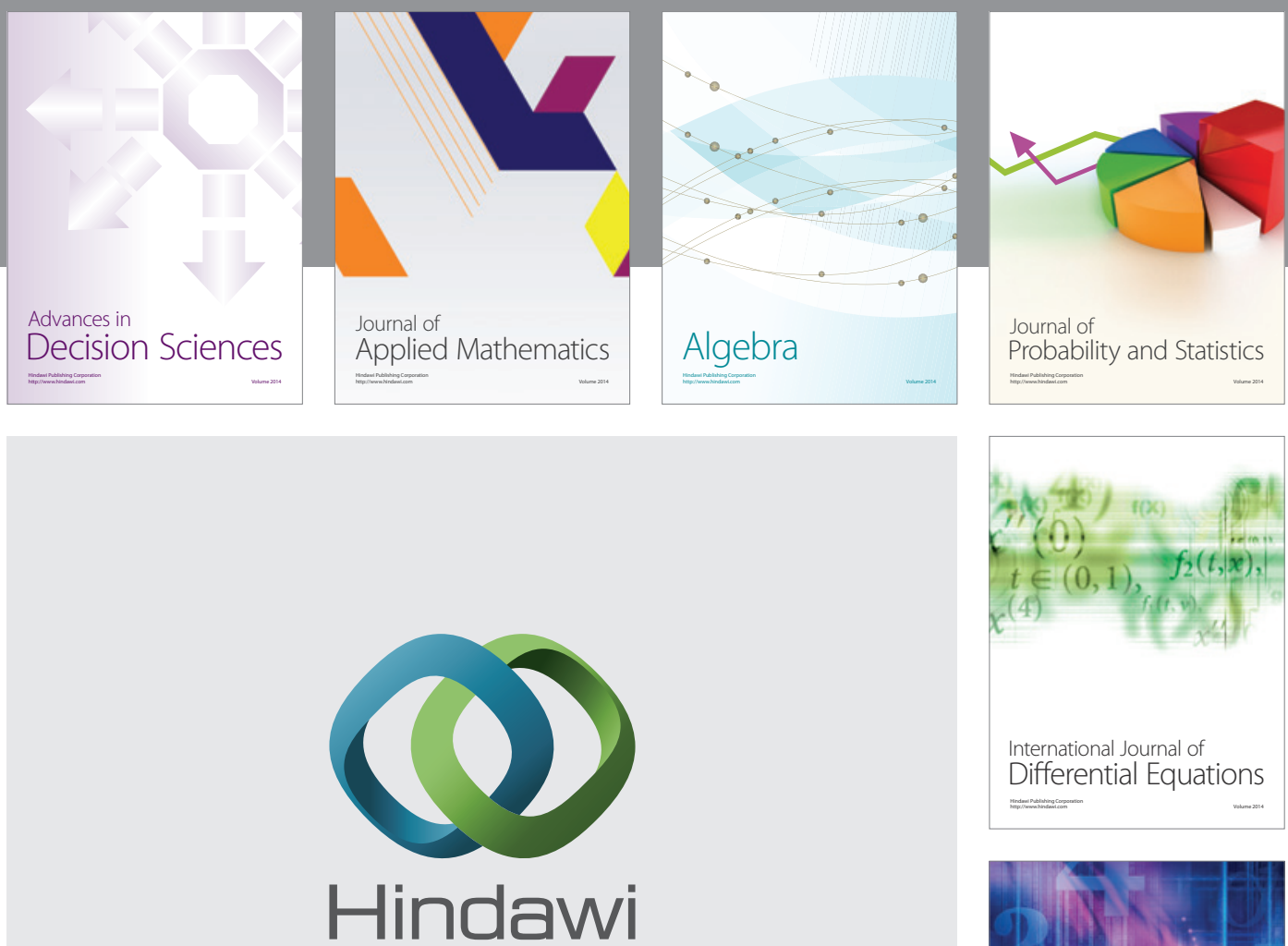

Submit your manuscripts at http://www.hindawi.com
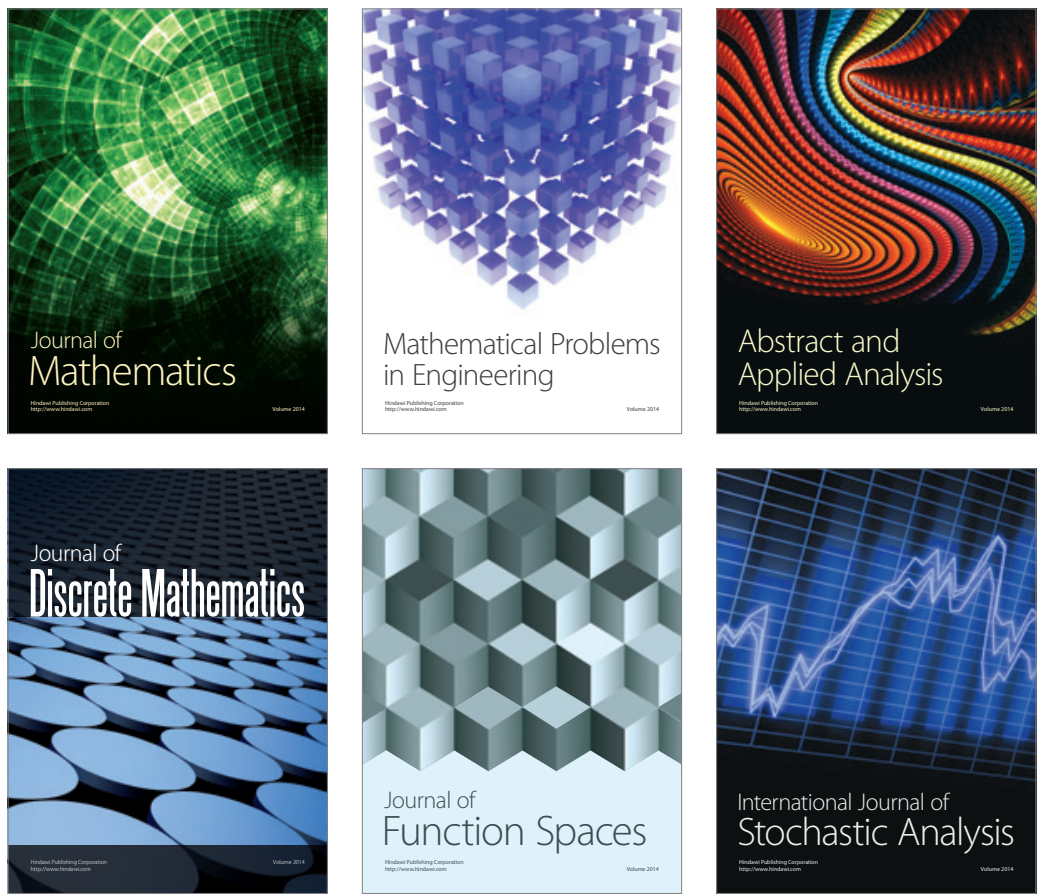

Journal of

Function Spaces

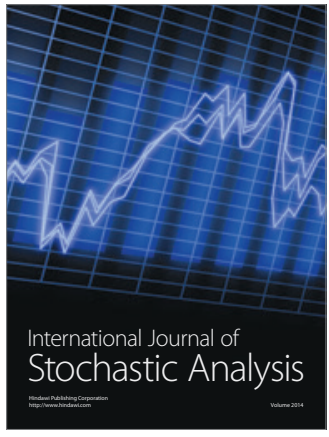

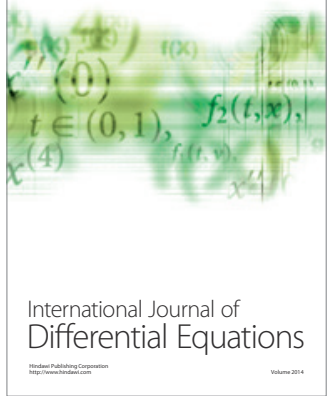
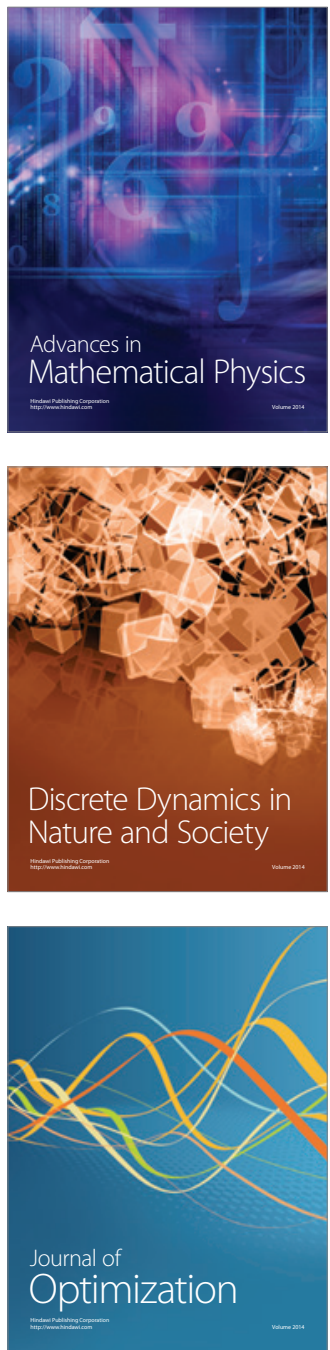